\title{
The electrochemical and spectroscopic characterization of 1,4 and 1,8-aminoanthraquinone derivatives
}

(INDEX: 56-61/2010 Copernican Letters ${ }^{\circledR}$ Vol 1)

\author{
Justyna Czupryniak, Paweł Niedziałkowski, Anna Bigot, Dorota Zarzeczańska, \\ Tadeusz Ossowski \\ University of Gdansk, Department of Analytical Chemistry, Sobieskiego 18/19, 80-952 \\ Gdansk \\ justynac@chem.univ.gda.pl
}

\begin{abstract}
The acid base properties of 1,4 and 1,8-anthraquinone derivatives were determined in methanol and acetonitrile by $\mathrm{pH}$-spectroscopic measurements. The examined compounds was also characterized by electrochemically using cyclic voltammetry in DMSO solutions.
\end{abstract}

\section{Introduction}

Anthraquinone and its derivatives are important compounds used in the field of dyes and pigments [1,2]. The dyeing and photochemical properties of them are often affected by the intermolecular interactions. With effective hydrogen donors and acceptors in their structures, hydrogen bond might be the dominant type of intermolecular interaction [3]. Besides hydrogen bond, the anthraquinone derivatives typically have large $p$-conjugated planar structures, which lead to other types of intermolecular interactions, such as interlayer $\pi-\pi$ interactions [4] and $\mathrm{C}-\mathrm{H}$ interactions [5]. Our investigation was focused on preparation and characterization of different functional organic based on anthraquinone moiety. We have synthesized two novel anthraquinone derivatives containing one or two symmetrical tertiary amine in the part of the structure and two other anthraquinone containing tertiary amine and such substituents as $-\mathrm{Cl}$ or -OTs in two different positions Fig. 1.<smiles>O=C1c2cccc(Br)c2C(=O)c2c([125I])ccc(Br)c21</smiles>

(1) $\mathrm{R}_{1}=\mathrm{H}$

(2) $\mathrm{R}_{1}=\mathrm{N}\left(\mathrm{CH}_{3}\right) \mathrm{CH}_{2} \mathrm{CH}_{2} \mathrm{OH}$ (4) $\mathrm{R}_{1}=\mathrm{H}$

$\mathrm{R}_{2}=\mathrm{N}\left(\mathrm{CH}_{3}\right) \mathrm{CH}_{2} \mathrm{CH}_{2} \mathrm{OH} \quad \mathrm{R}_{3}=\mathrm{OTs}$ $\mathrm{R}_{3}=\mathrm{H}$ $\mathrm{R}_{2}=\mathrm{N}\left(\mathrm{CH}_{3}\right) \mathrm{CH}_{2} \mathrm{CH}_{2} \mathrm{OH} \quad \mathrm{R}_{3}=\mathrm{N}\left(\mathrm{CH}_{3}\right) \mathrm{CH}_{2} \mathrm{CH}_{2} \mathrm{OH}$

Fig. 1. Structures of investigated 1,4 and 1,8 anthraquinone derivatives

\section{Experimental}

\subsection{Synthesis}

The compounds $(\mathbf{1}, \mathbf{2}, \mathbf{4})$ were obtained by the reaction of 2-(methylamino)ethanol with 1,4-bis(tosyloxy)-9,10-anthraquinone or 1,8-bis(tosyloxy)-9,10-anthraquinone. The compound (3) was obtained by the reaction of 2-(methylamino)ethanol with 1,8-dichloro-9,10-anthraquinone.

General procedures for the syntheses of compounds $(\mathbf{1}, \mathbf{2}, \mathbf{3}, \mathbf{4})$ :

To a solution of 1,4-, 1,8-bis(tosyloxy)9,10-anthraquinones or 1,8-dichloro-9,10anthraquinone in toluene, 2 (methylamino)ethanol and $\mathrm{Et}_{3} \mathrm{~N}$ were added. The solution was heated at $80^{\circ} \mathrm{C}$ or $100^{\circ} \mathrm{C}$ for $18-48 \mathrm{~h}$ with stirring under argon atmosphere. After evaporation of the solvent the reaction 
mixture was purified by column chromatography.

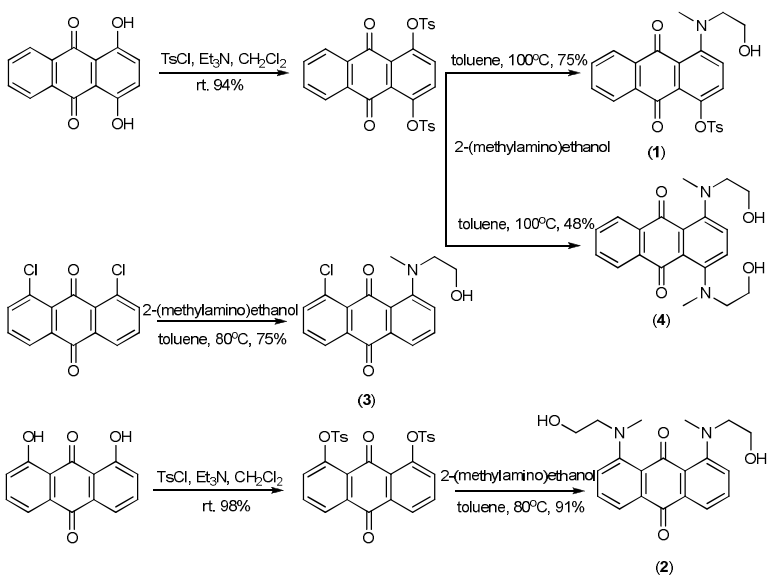

Fig. 2. Synthesis of compounds (1)-(4)

All synthesized compounds were purified by column chromatography on silica gel. They were characterized by MSTOF, NMR and IR techniques.

\subsection{Spectroscopic titrations}

Absorption spectra were obtained using a Perkin Elmer Lambda 650 spectrophotometer controlled by PERKIN ELMER (UV WinLab) software. The pathlength of the Suprasil quartz cell was $10 \mathrm{~mm}$, and the scan speed was $266 \mathrm{~nm}$ $\mathrm{min}^{-1}$, spectra were acquired between 280 and $800 \mathrm{~nm}$ in methanol and acetonitrylmethanol solutions. The titration system consisted of a titration cell, a magnetic stirrer, and an automatic titratory production Cerko Lab System with Hamilton's syringe $\left(0.5 \mathrm{~cm}^{3}\right)$. The $\mathrm{pH}$ combined electrode was bought from the Schott and it was calibrated on tetrabutylammonium 2,6-dinitrophenolate $[6,7]$.

The solutions of the compounds studied and tetrabutylammonium hydroxide base were prepared directly before measurements. Aliquots $(2.0 \mathrm{ml})$ of studied compunds, containing suitable amounts of methanesulfonic acid in methanol and acetonitrile were potentiometrically and spectrophotometric titrated with standard tetrabutylammonium hydroxide in methanol. The sample solution concentration ranged from 1 - $2 \mathrm{mM}$, and the acid-to-solution ratios employed ranged to $4: 1$.

The determination of the compound $\mathrm{pKa}$ values were performed using spectrophotometric measurements. The profile of absorbance obtained at the wavelength of the absorption maximum versus $\mathrm{pH}$ in each run was used to obtain the equilibrium constants using a Henderson-Hasselbach equation $[8,9]$.

\subsection{Electrochemical measurements}

The electrochemical investigations of four isomeric forms of 1,4-1,8aminoanthraquinone derivatives were carried out in a single-compartment, threeelectrode cell. The potential was applied with an Autolab potentiostat/galvanostat PGSTAT30 (Eco Chemie B.V., The Netherlands) controlled with General Purpose Electrochemical System (GPES 4.9) software. Before use, glassy carbon (GC) (diameter $0.3 \mathrm{~cm}$ ) electrode was sequentially polished on polishing clothes (Microcloth) with alumina (Buehler) pastes of decreasing particle size. Platinum wire was served as the counter electrode and a $\mathrm{Ag} / \mathrm{Ag}^{+}$system $\left(0.1 \mathrm{M} \mathrm{AgNO}_{3}, 0.1 \mathrm{M} \mathrm{KCl}\right)$ was used as the reference electrode.

The solutions consisted of a $0.1 \mathrm{M}$ tetrabutylammonium perchlorate in DMSO as a base electrolyte. All electrolyte solutions were sparged with argon prior to use in an effort to remove oxygen from the solutions. Experiments were performed at room temperature $\left(\sim 24^{\circ} \mathrm{C}\right)$. Voltammograms were scanned in a negative direction at a scan rate of $0.1 \mathrm{Vs}^{-1}$.

\section{Results and discussion}

3.1 Acid base properties in acetonitrile and methanol solutions 
The UV and visible absorption spectra of 1,4 and 1,8-aminoanthraquinone derivatives (1-4) in acetonitrile (Fig. 3) and methanol (Fig. 7) solutions display two absorption bands. The band 450-560 nm suffers a blue shifts as the polarity of the solvent increases and it is assigned to a $n-\pi^{*}$ transition. However the bands 270-400 nm are due to $\pi-\pi^{*}$ transitions. The acid - base behavior of aminoanthraquinone derivatives in organic media such as methanol is essential to predict the influence of $\mathrm{pH}$ on selectivity compounds. Therefore the $\mathrm{pKa}$ values for 1,4 and 1,8 -aminoanthraquinone derivatives was obtain.

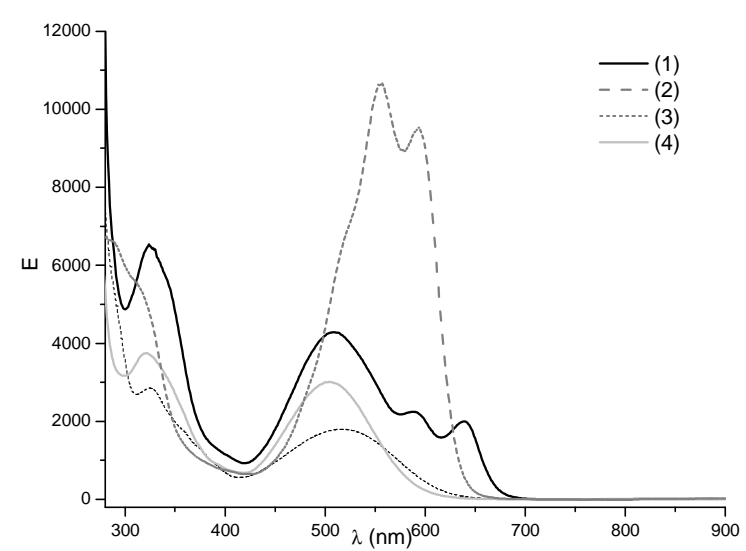

Fig. 3. The mass extinction coefficient $\varepsilon$ for compounds (1-4) in acetonitrile solution

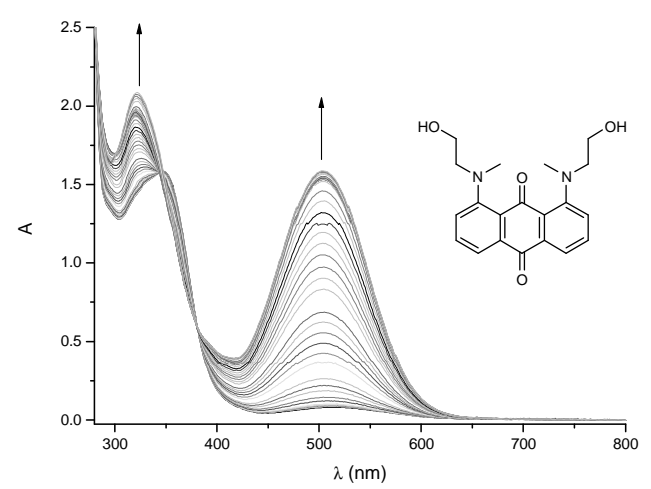

Fig. 4. Titration spectra for compound (2) dissolved in $\mathrm{CH}_{4} \mathrm{SO}_{3}$ in acetonitril titrated with tertbutylohydrooxide in methanol

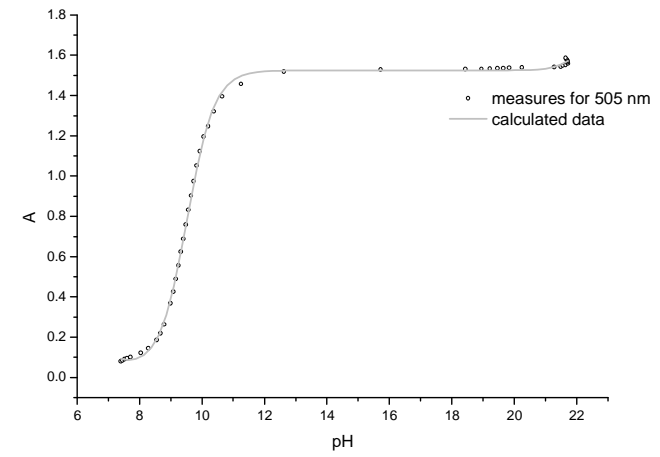

Fig. 5. Fitting of calculated data for measure in $\lambda=505 \mathrm{~nm}$ for compound (2) in acetonitril

a)

b)

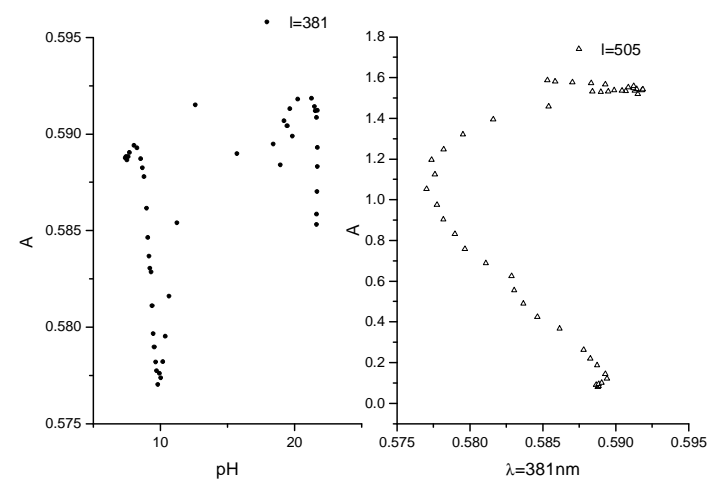

Fig. 6. Spectrophotometric titration curves for a) A vs. $\mathrm{pH}$ for $\lambda=381 \mathrm{~nm}, \mathrm{~b})$ A-diagram for $\lambda=505 \mathrm{~nm}$ vs. $\lambda=381 \mathrm{~nm}$ in acetonitril

Table 1

$\mathrm{pK}_{\mathrm{a}}$ values for 1,4 and 1,8-anthraguinone derivatives in acetonitrile

\begin{tabular}{|l|l|l|}
\hline Lp. & $\mathrm{pKa}_{1}$ & $\mathrm{pKa}_{2}$ \\
\hline & acetonitrile \\
\hline 1 & $8.97 \pm 0.03$ & $15.91 \pm 0.30$ \\
\hline 2 & $9.55 \pm 0.01$ & --- \\
\hline 3 & $7.61 \pm 0.04$ & $11.64 \pm 0.09$ \\
\hline 4 & $4.82 \pm 0.89$ & $17.76 \pm 0.61$ \\
\hline
\end{tabular}




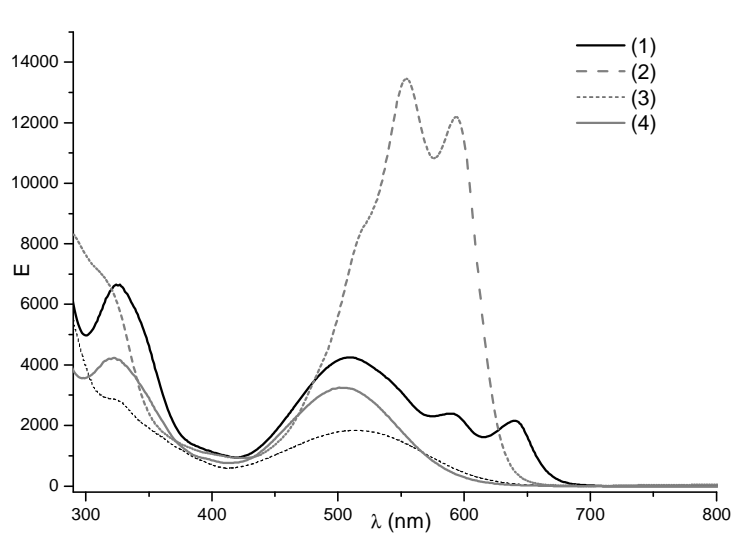

Fig. 7. The mass extinction coefficient $\varepsilon$ for compounds (1-4) in methanol solution

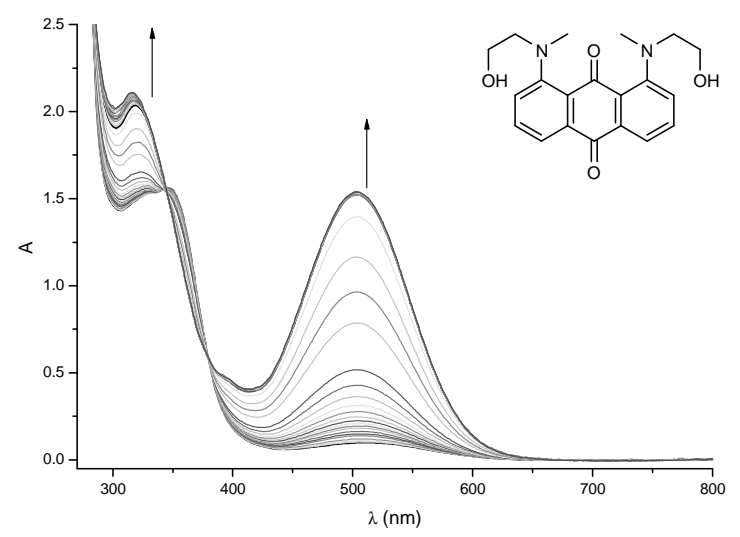

Fig. 8. Titration spectra for compound (2) dissolved in $\mathrm{CH}_{4} \mathrm{SO}_{3}$ in methanol titrated with tertbutylohydrooxide in methanol

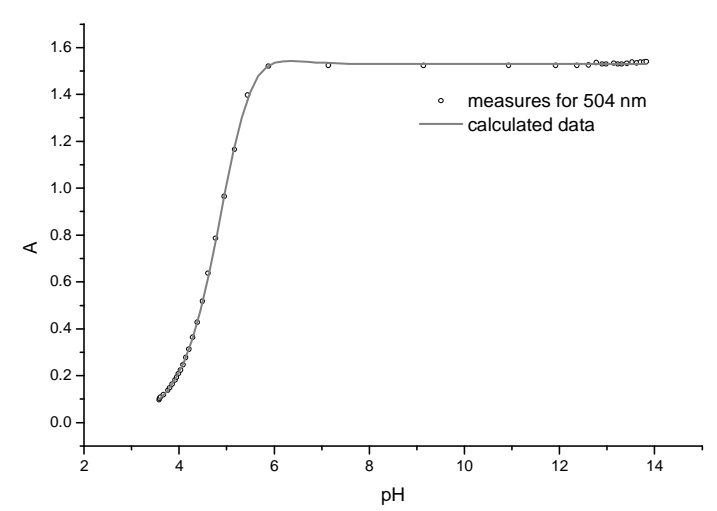

Fig. 9. Fitting of calculated data for measure in $\lambda=504$ $\mathrm{nm}$ for compound (2) in methanol a)

b)

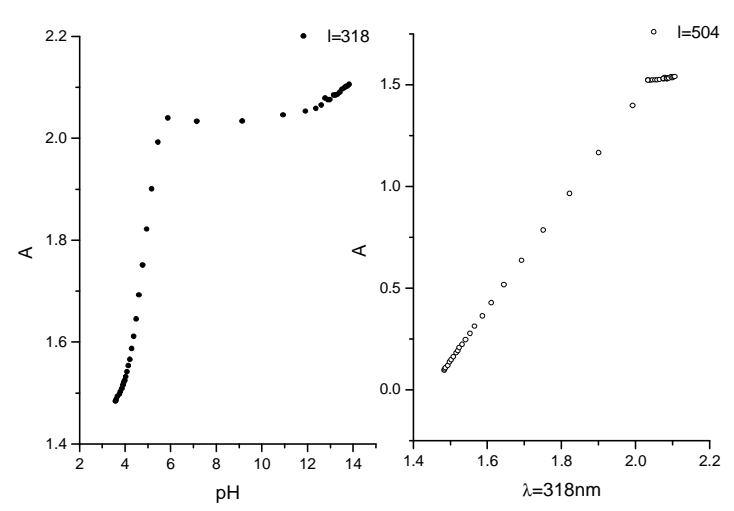

Fig. 10. Spectrophotometric titration curves for a) A vs. $\mathrm{pH}$ for $\lambda=381 \mathrm{~nm}, \mathrm{~b})$ A-diagram for $\lambda=504 \mathrm{~nm}$ vs. $\lambda=381 \mathrm{~nm}$ for compound (2) in methanol

Table 2

$\mathrm{pK}_{\mathrm{a}}$ values for 1,4 and 1,8-anthraguinone derivatives in methanol

\begin{tabular}{|l|l|l|}
\hline Lp. & $\mathrm{pKa}_{1}$ & $\mathrm{pKa}_{2}$ \\
\hline & methanol & \multicolumn{2}{|l|}{} \\
\hline 1 & $4.45 \pm 0.07$ & $5.25 \pm 0.07$ \\
\hline 2 & $5.51 \pm 0.11$ & $5.00 \pm 0.05$ \\
\hline 3 & $6.99 \pm 0.03$ & --- \\
\hline 4 & $10.59 \pm 0.7$ & $11.53 \pm 0.19$ \\
\hline
\end{tabular}

The acid dissociation of 1,4 and 1,8-aminoanthraquinone derivatives are summarized in Table 1 and 2. As shown, the highest $\mathrm{pKa}$ values occur in acetonitrile, while for methanol the values are by about $5 \mathrm{pKa}$ units lower. This is consistent with basicity of the solvent and with their capability of solvating the anthraquinone anions.

\subsection{Cyclic voltammetry in DMSO}

Quinone in non-aqueous and aprotic media (DMSO, DMF) show usually two separate redox processes. In these solvent reduction process has been attributed to two, one-electron redox steps according to following scheme $\mathrm{AQ}+\mathrm{e}=\mathrm{AQ}^{--}$and $\mathrm{AQ}^{--}+\mathrm{e}=\mathrm{AQ}^{2^{-}}$where reduction of the quinone species to the semiquinone anion is ensue by reduction to the fully reduced dianion. Research results from voltammetric measurements of investigated compounds are given in table 3 and 4 . 


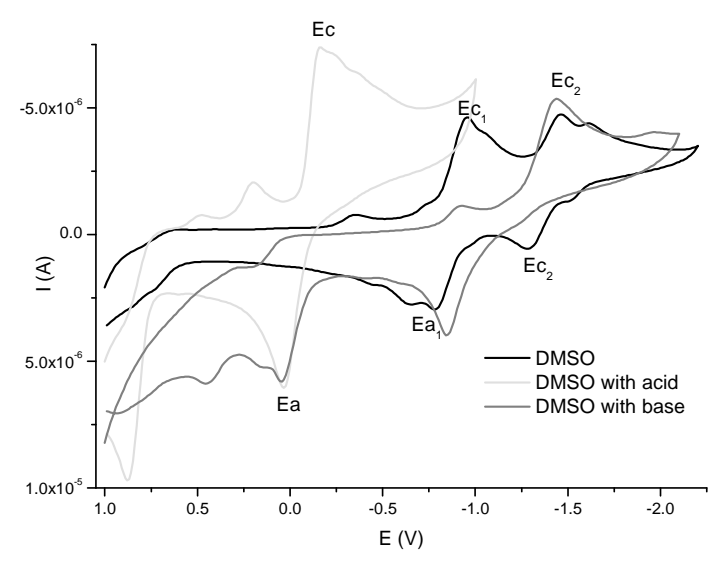

Fig. 11. Cyclic voltammograms of (1) obtained in DMSO solution recorded on glassy carbon electrode (ø $0.3 \mathrm{~cm})$ with scan rate $0.1 \mathrm{~V} \mathrm{~s}^{-1}$

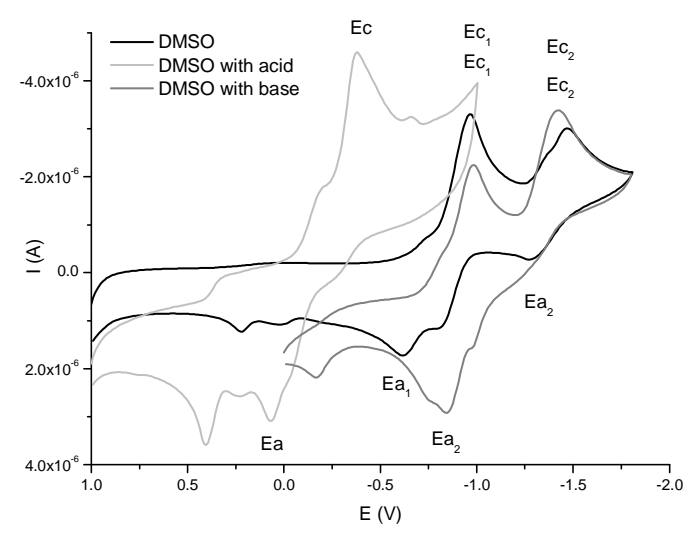

Fig. 12. Cyclic voltammograms of (2) obtained in DMSO solution recorded on glassy carbon electrode $(\varnothing 0.3 \mathrm{~cm})$ with scan rate $0.1 \mathrm{~V} \mathrm{~s}^{-1}$

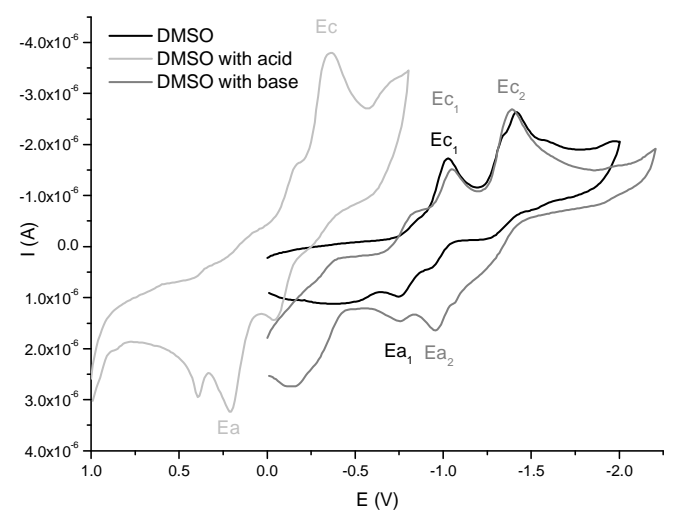

Fig. 13. Cyclic voltammograms of (3) obtained in DMSO solution recorded on glassy carbon electrode $(\varnothing 0.3 \mathrm{~cm})$ with scan rate $0.1 \mathrm{~V} \mathrm{~s}^{-1}$

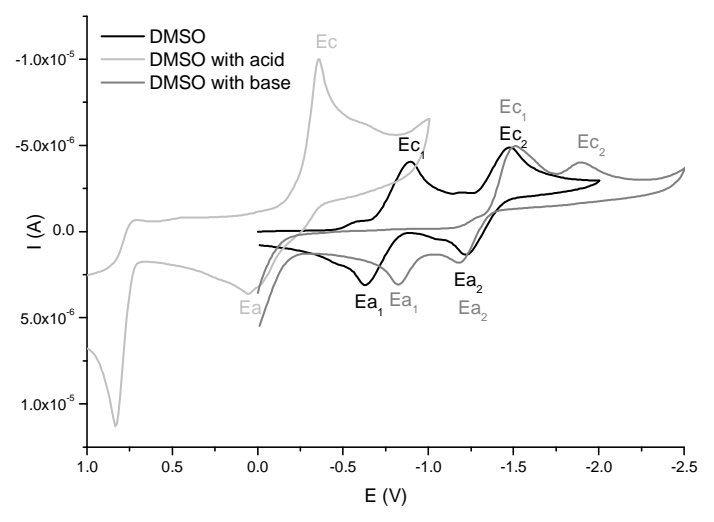

Fig. 14. Cyclic voltammograms of (4) obtained in DMSO solution recorded on glassy carbon electrode $(\varnothing 0.3 \mathrm{~cm})$ with scan rate $0.1 \mathrm{~V} \mathrm{~s}^{-1}$

Table 3.

Table of electrochemical constants

\begin{tabular}{|l|l|l|l|l|}
\hline \multirow{2}{*}{ Compound } & \multicolumn{3}{|l|}{$\mathrm{DMSO}$} \\
\cline { 2 - 5 } & $\mathrm{Ec}_{1}$ & $\mathrm{Ec}_{2}$ & $\mathrm{Ea}_{1}$ & $\mathrm{Ea}_{2}$ \\
\hline$(1)$ & -0.953 & -1.467 & -0.782 & -1.296 \\
\hline$(2)$ & -1.057 & -1.450 & -0.725 & -1.331 \\
\hline$(3)$ & -1.027 & -1.420 & --- & -0.755 \\
\hline$(4)$ & -0.963 & -1.467 & -0.621 & -1.276 \\
\hline
\end{tabular}

Table 4.

Table of electrochemical constants

\begin{tabular}{|l|l|l|l|l|l|l|}
\hline & \multicolumn{3}{|l|}{$\begin{array}{l}\text { DMSO } \\
\text { with acid }\end{array}$} & \multicolumn{3}{l|}{ DMSO with base } \\
\cline { 2 - 7 } & $\mathrm{Ec}$ & $\mathrm{Ea}$ & $\mathrm{Ec}_{1}$ & $\mathrm{Ec}_{2}$ & $\mathrm{Ea}_{1}$ & $\mathrm{Ea}_{2}$ \\
\hline$(1)$ & -0.158 & 0.033 & -1.427 & -0.85 & --- & --- \\
\hline$(2)$ & -0.36 & 0.053 & -1.510 & -1.90 & -0.83 & -1.18 \\
\hline$(3)$ & -0.35 & -0.05 & -1.047 & -1.39 & -0.96 & --- \\
\hline$(4)$ & -0.379 & 0.063 & -0.976 & -1.42 & -0.85 & --- \\
\hline
\end{tabular}

Electron transfer mediator properties of quinine derivatives of (1-4) were studied by cyclic voltammetry in DMSO, DMSO with acid and base (Fig. 11-14). The reduction sweep for all the derivatives consist of two major reversible or quasi reversible reduction waves (Table 3). The quinone derivatives (1-4) with acid addition displayed less negative reduction potentials compared to aminoanthraquinone derivatives in DMSO and DMSO with base. Thus will be able to accept electrons easily, it can be use as a indicator. 


\section{Conclusion}

In this paper we demonstrated that the modification of substituent of 1,4 and 1,8-aminoanthra uinone derivatives has a influence on spectroscopic acid-base properties and electrochemical behavior.

\section{Acknowledgements:}

The work was supported by the grant from Ministry of Education and Science

N N204 344037 in the year 2009-2011 and Grant BW/ 5210-5-0460-0.

\section{REFERENCES:}

[1] K. Hunger, Industrial Dyes: Chemistry, Properties, Application., Weinheim, Wiley-VCH., 2003.

[2] B.V. Rao, V. Choudhary, I.K.Varma, J. Soc. Dyers Colour 1990 106:388.

[3] Q. Meng, D. Huang, Dyes Pigments 2002 53:15.

[4] X. Zhang, R. Muenster, M. Jarasch, Mol. Cryst. Liq. Cryst. Sci.Technol. Sect A 1998 321:609.

[5] Q. Meng, W. Zhang, J. Yu, D. Huang, Dyes and Pigments 2005: 281-283.

[6] R. Wróbel, L. Chmurzyński, Anal.Chim. Acta 2000, 405, 303.

[7] L. Chmurzyński, A. Wawrzynów, Z. Pawlak, Electrochim. Acta 1990, 35, 665.

[8] S. Ebel, W. Parzefall, Experimetelle Einführung in die Potentiometrie, Verlag Chemie, Weinheim, 1975.

[9] J. Polster, H. Lachmann, Spectroscopic Titrations: Analysis of Chemical Equlibria, VCH, 1992. 